\title{
CITOGENÉTICA DE PEIXES NEOTROPICAIS: MÉTODOS, RESULTADOS E PERSPECTIVAS
}

\author{
NEOTROPICAL FISH CYTOGENETICS: METHODS, \\ RESULTS AND PERSPECTIVES
}

\author{
ROBERTO FERREIRA ARTONI ${ }^{1}$ \\ MARCELO RICARDO VICARI ${ }^{2}$ \\ LUIZ ANTONIO CARLOS BERTOLLO ${ }^{3}$ \\ 1 Professor do Departamento de Biologia \\ Geral da UEPG \\ 2 Acadêmico do curso de Licenciatura em \\ Ciências Biológicas da UEPG \\ 3 Professor Departamento de Genética e \\ Evolução da UFSCar
}

\begin{abstract}
RESUMO
São sintetizadas e brevemente comentadas metodologias básicas de estudo em citogenética de peixes, com vistas à introdução de estudos nessa área. Um apanhado geral das principais informações disponíveis na citogenética desse grupo, assim como algumas perspectivas de estudos nesse campo, são também discutidas.

Palavras-chave: citogenética; peixes; evolução cariotípica; perspectivas
\end{abstract}




\section{Introdução}

Os peixes representam o grupo mais diversificado e um dos mais interessantes para estudos da variabilidade genética e de evolução entre os vertebrados (Nelson, 1984).

Efetivamente, os primeiros trabalhos publicados sobre cariótipos de peixes neotropicais devem ser creditados a Jim e Toledo (1975), em duas espécies de Astyanax, Toledo e Ferrari (1976), em Pimelodidae, Michele et al. (1977a, 1977b), em Cichlidae e Loricariidae, respectivamente. Foi também na década de 70 que começaram a se formar os primeiros grupos de pesquisa nessa área, hoje presentes em vários estados brasileiros, alguns já muito bem consolidados, ao lado de outros mais recentes e em fase de consolid ação.

Segundo Oliveira et al. (1996), até o presente são conhecidos os números diplóides de 706 espécies, variando de 2 n=20 para Pterolebias longipinnis a $2 \mathrm{n}=134$ para Corydoras aeneus. Cromossomos sexuais são verificados para 40 espécies e 29 possuem cromossomos supernumerários;

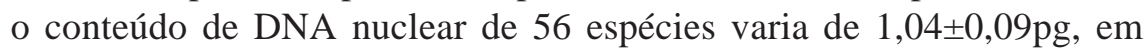
Corydoras cf. simulatus $(2 \mathrm{n}=62)$, a $8,75 \pm 1,50 \mathrm{pg}$, em Corydoras metae $(2 n=92)$. Considerando que a ictiofauna de água doce do neotrópico pode atingir até 5000 espécies, tem-se que o número de espécies citogeneticamente investigadas é bastante diminuto, frente à diversidade encontrada nesta região. No entanto, de uma forma bastante abrangente, a quase totalidade das famílias de peixes neotropicais possuem espécies com algum tipo de informação acerca de seus cromossomos sendo, portanto, de grande relevância os dados obtidos até o presente, os quais contribuem para o conhecimento da biologia, sistemática e evolução desse importante grupo de vertebrados.

O presente artigo apresenta metodologias básicas de estudos em citogenética de peixes, destacando tendências gerais da evolução cariotípica do grupo e algumas perspectivas relacionadas a essa área.

\section{Metodologias básicas em citogenética de peixes}

\subsection{Coleta}

PUBLICATIO UEPG - Biological and Health Sciences, 6 (1): 43-60, 2000. 
Os espécimes podem ser coletados diretamente na natureza ou provenientes de estações de piscicultura. A coleta é sempre realizada com o auxílio de material de pesca (redes, tarrafas, peneiras, etc), sendo essencial o trabalho com espécimens vivos. Os animais são transportados e acondicionados em sacos plásticos, com água e oxigênio ou mesmo em caixas de isopor, em condições que possam garantir sua sobrevivência. No laboratório, os peixes são aclimatados em aquários bem aerados onde permanecem até sua utilização.

\section{2. Processamento}

A exemplo do que ocorre em outros grupos de animais, diversas técnicas têm sido utilizadas para o estudo de cromossomos em peixes, algas amplamente utilizadas, ao lado de outras mais restritas, por exigirem condições mais especiais para sua utilização. Deter-nos-emos, aqui, na descrição de alguns métodos mais convencionais de estudo, que possibilitam obter os resultados necessários para uma análise cromossômica básica e inicial nesse grupo.

\subsubsection{Preparações cromossômicas}

Um dos procedimentos mais utilizados para a obtenção de cromossomos mitóticos é o método convencional de "air-drying", a partir de uma suspensão celular hipotonizada e fixada, adaptada inicialmente para peixes por Bertollo et al. (1978). Acloplada a esse método pode-se também adotar a estimulação de mitoses pela ação de leveduras, com intuito de aumentar o número de células em divisão, o que é uma condição essencial para os estudos cromossômicos. Assim sendo, injeta-se subcutaneamente uma solução de fermento biológico sacarosado ( $5 \mathrm{~g}$ fermento: $3 \mathrm{~g}$, dextrose: $10 \mathrm{ml}$ água), $1 \mathrm{ml}$ para cada $100 \mathrm{~g}$ de peso do animal (LEE e ELDER, 1980). Após 24 horas de ação desse indutor mitótico, injeta-se intraperitonialmente uma solução de colchicina $(0,025 \%), 1 \mathrm{ml}$ para cada $100 \mathrm{~g}$ de peso corporal, a fim de se obter células mitóticas metafásicas.

Após 50-60 minutos da aplicação da colchicina, os animais são sacrificados removendo-se o rim, que nos peixes é um órgão hematopoiético e naturalmente apresenta células em divisão (MOREIRA-FILHO e BERTOLLO, 1991a). Fragmentos desse órgão (cerca de $5 \mathrm{~mm}^{3}$ ) são 
transferidos para uma cubeta de vidro contendo cerca de10ml de solução hipotônica (KCl 0,075M) e com o auxílio de duas pinças, fragmenta-se bem o material, complementando-se esse processo por aspirações e eliminações sucessivas do material em uma seringa de vidro desprovida de agulha, até que se obtenha uma suspensão celular bem homogênea.

A hipotonização celular é feita pela incubação do material em estufa a $37^{\circ} \mathrm{C}$, por 20 minutos. Após este tempo a suspensão é transferida para um tubo de centrífuga e centrifugada por 10 minutos a $1000 \mathrm{rpm}$. O sobrenadante é descartado com uma pipeta de Pasteur, procedendo-se então à fixação das células.

Figura 1. Metáfase mitótica de Astyanax cf. eigenmaniorum da Furna 1 do Parque Estadual de Vila Velha (PR) obtida através de preparação direta de cromossomos a partir de células de rim. Em (A) coloração convencional dos cromossomos pelo Giemsa. Em (B), a mesma metáfase de (A) tratada seqüencialmente para obtenção do padrão de distribuição da heterocromatina constitutiva sobre os cromossomos. Ambas estão destacadas pelas cabeças de setas. 
A fixação é realizada acrescentando-se cerca de $10 \mathrm{ml}$ de fixador (metanol e ácido acético 3:1 recém-preparado) no tubo de centrífuga, ressuspendendo-se o material com uma pipeta de Pasteur, seguindo-se nova centrifugação por 10 minutos a $1000 \mathrm{rpm}$. Esse procedimento deve ser repetido por mais 1-2 vezes, com troca do fixador. Após a última centrifugação e descarte do fixador, adiciona-se $1,0 \mathrm{ml}$ de fixador novo e o material está pronto para ser analisado. As células podem ser gotejadas em uma lâmina bem limpa, aquecida ao redor de $40^{\circ} \mathrm{C}$. A sobra do material pode ser guardada em tubos tipo Eppendorf, em freezer, para posterior utilização.

As lâminas podem ser coradas em solução de Giemsa tamponada (pH 6,8) a 5\%, durante 6-7 minutos, lavadas em água corrente e secadas ao ar. O exame pode ser realizado em microscópio ótico de campo claro, em aumento de 1000 vezes (Figura 1A).

\section{2. 2. Bandamentos cromossômicos}

Entre as técnicas utilizadas rotineiramente em citogenética de peixes destacam-se o bandamento C (banda-CBG) e impregnação das regiões organizadoras de nucléolos pelo nitrato de prata (Ag-RONs) uma vez que bandamentos longitudinais, tipo bandamento G (banda-GTG), são menos facilmente obtidos em cromossomos de peixes.

O bandamento C, para a coloração diferencial da heterocromatina constitutiva, baseia-se na técnica de Sumner (1972). Hidrolisa-se previamente o material em ácido clorídrico $(\mathrm{HCl}$ a $0,2 \mathrm{~N})$ por 10 minutos, a $37^{\circ} \mathrm{C}$. Lava-se em água destilada e incuba-se a lâmina em solução de hidróxido de bário $\left(\mathrm{Ba}(\mathrm{OH})_{2}\right)$ a $5 \%$, recém preparada e filtrada, a $42^{\circ} \mathrm{C}$. Bons resultados são obtidos com incubação feita entre 1 e 2 minutos em lâminas com 1 dia de envelhecimento em temperatura ambiente, dependendo da fixação do material. Após lavagem rápida da lâmina em $\mathrm{HCl}$ 0,2 N e em água destilada, para retirar o resíduo de hidróxido de bário utilizado na desnaturação do DNA, incuba-se a lâmina em solução salina de citrato de sódio (2xSSC) a $60^{\circ} \mathrm{C}$, durante 1 hora para melhor diferenciação das bandas. A seguir corase em solução de Giemsa tamponada a 2\% (pH 6,8) durante 15 minutos e analisa-se ao microscópio de campo claro (Figura 1B e 2B).

A detecção das regiões organizadoras de nucléolos pode ser obtida pela técnica de impregnação pelo nitrato de prata (Ag-RONs), descrita por 
Howell e Black (1980). Coloca-se sobre as preparações cromossômicas 1 gota $( \pm 150 \mathrm{ml})$ de solução de gelatina $(1 \%)$ e 2 gotas $( \pm 300 \mathrm{ml})$ de solução aquosa de nitrato de prata (50\%). Mistura-se levemente com a ponta de uma lamínula, tomando cuidado para não riscar o material. Cobre-se a lâmina com uma lamínula (60x20mm) e mantém-se em estufa a $60^{\circ} \mathrm{C}$, o tempo necessário para que os cromossomos e núcleos assumam uma coloração amarelada e os nucléolos e as RONs uma coloração quase preta. Em geral, esse tempo varia entre 3 a 5 minutos. Remove-se então a lamínula com um jato de água destilada, lavando-se bem o material. Após secagem ao ar, pode-se examinar a preparação em microscópio de campo claro.

Opcionalmente, as lâminas podem ser também coradas com solução de Giemsa a 1\%, por 1 minuto. (Figura 3).

Figura 2. Cariótipos de Triportheus guentheri do rio São Francisco (MG). Em (A) cariótipo de um exemplar macho submetido à coloração convencional com Giemsa. Em (B) cariótipo de fêmea submetido ao bandamento C, com destaque para a presença do primeiro par de cromossomos heteromórficos quanto à morfologia e heterocromatina constitutiva, evidenciando um sistema de cromossomos sexuais do tipo ZZ/ZW.

PUBLICATIO UEPG - Biological and Health Sciences, 6 (1): 43-60, 2000. 
Figura 3. Metáfase mitótica de Triportheus guentheri do rio São Francisco (MG) submetida à coloração das regiões organizadoras do nucléolo pelo nitrato de prata (Ag-RONs), destacadas pelas cabeças de setas.

\section{2. 3. A organização do cariótipo de peixes}

Distintamente do que ocorre em vários outros grupos animais, não há ainda um padrão pré-estabelecido para a ordenação dos pares cromossômicos no cariótipo de peixes.

Em peixes tem sido bastante utilizada a ordenação dos cromossomos em ordem decrescente de tamanho (Figura 2). No entanto, os cromossomos têm sido também agrupados por tipos morfológicos em classes distintas (Figura 4), sendo classificados pela relação de braços (RB), em metacêntricos $(\mathrm{RB}=1,00$ a 1,70), submetacêntricos $(\mathrm{RB}=1,71$ a 3,00), subtelocêntricos $(\mathrm{RB}=3,01$ a 7,00) e acrocêntricos (RB a partir de 7,01) (Levan et al., 1964). 
Figura 4. Cariótipo de Pogonopoma wertheimeri do rio Mucuri (BA), corado com Giemsa, evidenciando 2n=54 cromossomos organizados em metacêntricos (M), submetacêntricos (SM) e subtelo-acrocêntricos (ST/A).

\section{Os estudos cromossômicos em peixes neotropicais}

A região neotropical apresenta a ictiofauna de água doce mais rica e diversa de todo o mundo. As duas ordens mais representativas em número de espécies conhecidas nesta região são os Characiformes e os Siluriformes, vulgarmente chamados de peixes de escamas e de couro, respectivamente. Nos últimos anos, a citogenética de peixes vem acumulando dados que permitem estabelecer tendências evolutivas entre as diferentes famílias destas ordens.

Os Characiformes, assim como os Siluriformes, mostram uma ampla variabilidade cariotípica. Dentre estes, observam-se grupos com cariótipos bastante heterogêneos, ao lado de outros bem mais conservados na estrutura cariotípica.

Os Characiformes exibem uma ampla variação no número diplóide. Assim, observam-se casos como em Hemigrammus, com 2n = 28 (SCHEEL, 1973) e em Potamorhina altamazonica, com 2n = 102 (FELDBERG et al., 
1993). Ainda entre os Characiformes, de modo geral, existem dois padrões de diversificação cromossômica. No primeiro, grupos, famílias como Erythrinidae ou gêneros como Astyanax mostram grande variabilidade quanto ao número e estrutura cromossômica e, no segundo grupo, famílias como Anostomidae, Curimatidae, Prochilodontidae, Chilodontidae, Hemiodontidae e Parodontidae mostram pequena variação numérica e estrutural no cariótipo (BERTOLLO et al., 1986; GALETTI JR. et al., 1994). De fato, vários desses últimos grupos têm sido considerados monofiléticos (VARI, 1983; MOREIRA-FILHO et al., 1985; VENERE e GALETTI JR., 1989; PORTO et al., 1993; GALETTI JR. et al., 1994).

Ainda entre os Characiformes, conhecem-se vários exemplos de ocorrência de cromossomos supranumerários, como em Apareiodon piracicabae e Paraligosarcus pintoi (FALCÃO et al., 1984), Prochilodus lineatus e $P$. cearensis (PAULS e BERTOLLO, 1983, 1990), Leporinus friderici e Prochilodus nigricans (VENERE, 1998), Curimata modesta (VENERE e GALETTI JR., 1985; VENERE, 1991; MARTINS et al., 1996), Steindarchnerina insculpta (OLIVEIRA e FORESTI, 1993), Schizodon (PASTORI et al., 1997). Estes são cromossomos adicionais àqueles do complemento cariotípico padrão e que, quase sempre, mostram-se heterocromáticos. Podem representar eventos esporádicos ou mesmo uma característica comum de determinadas populações. Na família Characidae, Astyanax scabripinnis se destaca como a espécie que tem sido atualmente mais estudada quanto aos cromossomos supranumerários, no que se refere à sua distribuição, comportamento e origem (SALVADOR e MOREIRA FILHO, 1992; MAISTRO et al., 1992; STANGE e ALMEIDA-TOLEDO, 1993; MESTRINER, 1997; VICENTE et al., 1996, entre outros).

Em Siluriformes, vários estudos citogenéticos vêm sendo conduzidos nas subordens Gymnotoidei e Siluroidei. Entre os Gymnotoidei, verifica-se uma diversidade cariotípica relativamente ampla, com diferenças tanto na estrutura como no número cromossômico. Esta diversidade pode ser comprovada nos gêneros Eigenmannia (ALMEIDA-TOLEDO, 1978; ALMEIDA-TOLEDO et al., 1984) e Gymnotus (FORESTI et al., 1984). Na subordem Siluroidei, a estrutura cariotípica parece ser mais conservada, sendo que $2 \mathrm{n}=56 \pm 2$ deve representar o número cromossômico basal (LE GRANDE, 1981, entre outros). Contudo, mesmo neste último grupo existem exemplos de intensa diversificação cariotípica, como em Loricariidae com número cromossômico diplóide variando de $2 n=44$ a 80 (ARTONI e 
BERTOLLO, 1999; ARTONI, 1996; ARTONI et al., 1998).

Entre os Siluriformes, o gênero Rhamdia (Pimelodidae) mostra a ocorrência de cromossomos supranumerários em diferentes populações (HOCHBERG e ERDTMANN, 1988; FENOCCHIO e BERTOLLO, 1990). Em um outro Pimelodidae, Bergiaria westermanni (DIAS e FORESTI, 1993), essa ocorrência também foi observada. Da mesma forma, na subfamília Loricariinae podem ser encontrados exemplos de polimorfismos devido à presença de cromossomos supranumerários (SCAVONE e JULIO JR., 1995).

Outro aspecto de destaque na estrutura cariotípica dos peixes diz respeito à presença de cromossomos sexuais. Os peixes, diferentemente das aves e mamíferos, não apresentam cromossomos sexuais na base de sua filogenia. Assim, esse caráter deve ter surgido de forma independente e repetida na história evolutiva desse grupo, onde algumas espécies apresentam cromossomos sexuais bem diferenciados, embora essa ocorrência não seja freqüente.

Sistemas de cromossomos sexuais com heterogametia feminina (ZZ/ ZW) são encontrados principalmente em algumas espécies dos gêneros Leporinus (GALETTI JR. et al., 1981; GALETTI JR. et al., 1995; MOLINA, 1995), Parodon (MOREIRA-FILHO et al., 1993), Loricariichthys (SCAVONE e JULIO JR., 1995), Microlepidogaster (ANDREATA et al., 1992, 1993), Hypostomus (ARTONI et al., 1998) e Triportheus (FALCÃO et al., 1984; ARTONI, 1999). Na maioria desses casos fica evidente que a diferenciação dos cromossomos sexuais foi acompanhada por um processo de heterocromatinização e alteração de tamanho do cromossomo W. Entretanto, em peixes neotropicais, as primeiras ocorrências de cromossomos sexuais foram verificadas nos gêneros Hoplias, com sistemas de cromossomos sexuais múltiplos $\mathrm{X}_{1} \mathrm{X}_{1} \mathrm{X}_{2} \mathrm{X}_{2} / \mathrm{X}_{1} \mathrm{X}_{2} \mathrm{Y}$ e $\mathrm{XX} / \mathrm{XY}_{1} \mathrm{Y}_{2}$ (BERTOLLO et al., 1978) e em Eigenmannia, com sistema $\mathrm{X}_{1} \mathrm{X}_{1} \mathrm{X}_{2} \mathrm{X}_{2}{ }^{\prime}$ $\mathrm{X}_{1} \mathrm{X}_{2} \mathrm{Y}$ (ALMEIDA-TOLEDO, 1978). Sistemas XX/XY foram descritos em Pseudotocinclus tietensis (Loricariidae) e também no gênero Hoplias (ANDREATTA et al., 1992; BORN e BERTOLLO, 2000), respectivamente.

Um único caso de cromossomos sexuais múltiplos, com heterogametia feminina, (ZZ/Z W $\mathrm{W}_{2}$ ) foi relatado em Apareiodon affinis (MOREIRAFILHO et al., 1980). 


\section{Perspectivas para a citogenética de peixes}

A maior aplicabilidade da citogenética de peixes, sem dúvida alguma, se refere aos estudos evolutivos. Como uma extensão desses estudos, encontramos na literatura inúmeras associações com a Taxonomia. A citotaxonomia tem constituído um dos objetivos da citogenética de peixes neotropicais, principalmente em grupos taxonomicamente problemáticos (BERTOLLO et al., 1986; MOREIRA-FILHO e BERTOLLO, 1991b, entre outros), podendo ser considerada uma excelente ferramenta para ser utilizada em associação com dados de morfologia, biogeografia, comportamento e genética molecular, para se chegar mais próximo a uma real história evolutiva dos organismos.

Nas últimas décadas, a citogenética teve um impulso significativo no seu espectro de atuação. A utilização de técnicas de manipulação do material genético associadas à detecção de sequiências específicas de DNA fez nascer o que se conhece hoje por Citogenética Molecular. Especialmente neste caso, o fator fundamental para a expansão desses estudos foi a utilização de marcações não-radioativas do DNA, com o emprego de corantes fluorescentes, detectadas por hibridação in situ (FISH).

Apesar dos peixes começarem hoje a ser utilizados até mesmo como modelo de regulação da expressão gênica durante o desenvolvimento, estudos estes iniciados com a obtenção de clones homozigotos diplóides em zebra fish (Brachydanio rerio) (STREISINGER et al., 1981), as análises de mapeamento gênico, seqüenciamento de fragmentos de DNA e hibridizações em membrana e/ou in situ não são ainda freqüentes nesse grupo. Aspectos de genética molecular e imunocitogenética de peixes brasileiros foram recentemente abordados por Almeida-Toledo (1996).

Alguns estudos têm utilizado a identificação de DNA satélite em análises populacionais, assim como da própria organização do DNA no genoma de peixes (HAAF et al., 1993). Bertollo e Mestriner (1998) sugerem que uma das subfamílias de DNA satélite caracterizadas por Haaf et al. (op. cit.) pode estar relacionada aos cromossomos sexuais dessa espécie, uma vez que o cromossomo portador desse tipo de DNA é, aparentemente, o mesmo cromossomo identificado como $X_{1}$, em um sistema de cromossomos sexuais múltiplos do tipo $\mathrm{X}_{1} \mathrm{X}_{1} \mathrm{X}_{2} \mathrm{X}_{2} / \mathrm{X}_{1} \mathrm{X}_{2} \mathrm{Y}$. A localização do DNA satélite nos cromossomos de Astyanax scabripinnis tem também fortalecido a proposta de que o cromossomo supranumerário mais presente nessa espécie seja um isocromossomo (MESTRINER et al., in press). 
Em Sparus aurata (Sparidae) uma família de DNA altamente repetitivo, Eco RI, foi isolada por Garrido-Ramos et al. (1994) e localizada em todos os cromossomos dessa e de outras espécies da mesma família. A conservação da seqüência repetitiva entre diferentes espécies e a semelhança de uma seqüência menor (9pb) dessa famíla Eco RI, com seqüências centroméricas de outros vertebrados, como anfíbios e mamíferos, sugere que este DNA satélite seja um elemento estrutural e/ou funcional de centrômero (GARRIDO-RAMOS et al., 1995).

Em piscicultura, a utilização de marcadores cromossômicos tem se mostrado de importância na identificação de híbridos interespecíficos como nos casos dos tambaquis (Piaractus mesopotamicus) e pacus (Colossoma macropomum) (FORESTI et al., 1986; ALMEIDA-TOLEDO et al., 1987, 1993) e na verificação da ploidia em poliplóides induzidos artificialmente, como na carpa Cyprinus carpio (GERVAI et al., 1981), na truta arco-íris Salmo gairdneri (REFESTIE, 1981) e no ciclidae Rhodeus ocellatus ocellatus (UENO e ARIMOTO, 1982), entre outros.

A Citogenética tem se mostrado uma ciência dinâmica que se adapta às necessidades e às novas tecnologias, mantendo-se sempre como uma área em destaque na Genética. Assim, especialmente em peixes, onde são vários os problemas já levantados, juntamente com outros que surgem a todo momento, há muito a ser ainda investigado no campo dos cromossomos.

\section{Agradecimentos}

Os autores são especialmente gratos a Dr. Orlando Moreira-Filho e Dr. Pedro Manoel Galetti Júnior do laboratório de Citogenética de Peixes da Universidade Federal de São Carlos, ao sr. Miguel Airton Carvalho pelo trabalho tecnológico e à Universidade Estadual de Ponta Grossa pelo apoio.

Recebido para publicação em 12/08/00. Aceito para publicação em 22/11/00.

\section{ABSTRACT}

This work summarizes a basic methodology in fish cytogenetics, with the aim of introducing fundamental studies in this area. A general comment on available 
information is included, and some perspectives for studies in this field are also discussed.

Key words: cytogenetics; fish; karyotypic evolution; perspectives

Endereço para contato: rasartoni@uol.com.br

\section{REFERÊNCIAS}

1 ALMEIDA-TOLEDO, L. F. Contribuição à citogenética de Gymnotoidei (Pisces, Osthariophysi). São Paulo, 1978. Tese (Doutorado) - Universidade de São Paulo.

2 ALMEIDA-TOLEDO, L. F. Molecular and immunocytogenetics of Brazilian fishes. Cien. Cult., 20, p. 377-382. 1996.

3 ALMEIDA-TOLEDO, L. F.; FORESTI, F.; TOLEDO-FILHO, S. A. Complex sex chromosome system. In: Eigenmannia sp. (Pisces, Gymnotiformes). Genetica, v. 64, n. 3, p. 165-169. 1984.

4 AlMEIDA-TOLEDO, L. F.; TOLEDO-FILHO, S. A.; FORESTI, F.; BERNARDINO, G.; FERRARI, W.; ALCÂNTARA, R. C. G. Cytogenetic studies in Colossoma mitrei, C. macropomum and their interespecific hybrids. In: Selection hybridization and engeneering in aquaculture. K. Tiews : Berlin, v. 1, p. 190-195. 1987.

5 ALMEIDA-TOLEDO, L. F.; COUTINHO-BARBOSA, A. C.; ROSENBERG, C.; DANIEL, M. F. Z.; TOLEDO-FILHO, S. A. Hibridação in situ com sondas de rDNA em cromossomos de Piaractus mesopotamicus, Colossoma macropomum e de seus híbridos. Braz. J. Genet., v. 16 (Suplement), p. 141. 1993.

6 ANDREATA, A. A.; ALMEIDA-TOLEDO, L. F.; OLIVEIRA, C.; TOLEDOFILHO, S. A. Chromosomes studies in Hypoptopomatinae (Pisces, Siluriformes, Loricariidae): I. XX/XY sex chromosome heteromorphism in Pseudotocinclus tietensis. Cytologia, v. 57, p. 369-372. 1992.

7 ANDREATA, A. A.; ALMEIDA-TOLEDO, L. F.; OLIVEIRA, C.; TOLEDOFILHO, S. A. Chromosomes studies in Hypoptopomatinae (Pisces, Siluriformes, Loricariidae): II. ZZ/ZW sex chromosome system, B chromosomes and constitutive heterochromatin diferentiation in Microlepidogaster leucofrenatus. Cytogenet. Cell. Genet., v. 63, p. 215-220. 1993. 
8 ARTONI, R. F. Estudos citogenéticos na família loricariidae, com ênfase no gênero Hypostomus Lacépède (1803) (Pisces, Loricariidae, Hypostominae). São Carlos, 1996. 162 p. Dissertação (Mestrado). UFSCar - SP.

9 ARTONI, R. F. Citogenética do sistema de cromossomos sexuais ZZ/ZW no gênero Triportheus (Pisces, Characidae). São Carlos, 1999. 162 p. Tese (Doutorado). UFSCar.

10 ARTONI, R. F.; BERTOLLO, L. A. C. Cytogenetic studies on Hypostominae (Pisces, Siluriformes, Loricariidae). Considerations on karyotype evolution in the genus Hypostomus. Caryologia, v. 49: 1, p. 81-90. 1999.

11 ARTONI, R. F.; MOLINA, W. F.; BERTOLLO, L. A. C.; GALETTI JR., P. M. Heterochromatin analysis in the fish species Liposarcus anisitsi (Siluriformes) and Leporinus elongatus (Characiformes). Genet. Mol. Biol., v. 22: 1, p. 39-44. 1999.

12 ARTONI, R. F.; BERTOLLO, L. A. C. Nature and distribution of constitutive heterochromatin in fishes, genus Hypostomus (Loricariidae). Genetica, v. 106: p. 209-214. 1999.

13 ARTONI, R. F.; VENERE, P. C.; BERTOLLO, L. A. C. A heteromorphic ZZ/ZW sex chromosome system in fish, genus Hypostomus (Loricariidae). Cytologia, v. 63, p. 421-425. 1998.

14 Bertollo, L. A. C.; TAKAHASHI, C. S.; MOREIRA-FILHO, O. Cytotaxonomic considerations on Hoplias lacerdae (Pisces, Erythrinidae). Braz. J. Genet., v. 2, n.1, p.17-37. 1978.

15 BERTOLLO, L.A. C.; MOREIRA-FILHO, O.; GALETTI JR., P. M. Cytogenetics and taxonomy: consideration based on chromosome studies of freshwater fish. $\mathbf{J}$. Fish. Biol., v. 28, p. 153-159. 1986.

16 BERTOLLO, L. A. C.; MESTRINER, C. A. The $\mathrm{X}_{1} \mathrm{X}_{2} \mathrm{Y}$ sex chromosome system in the fish Hoplias malabaricus. Chromosome Res., v. 6, p. 141-147. 1998.

17 BORN, G. G.; BERTOLLO, L. A. C. Na XX/XY sex chromosome system in a fish specie, Hoplias malabaricus, with a polymorphic NOR-bearing X chromosome. Chromosome. Res., v. 8, p. 111-118. 2000.

18 DIAS, A. L.; FORESTI, F. Cytogenetic studies on fishes of the family Pimelodidae (Siluroidei). Braz. J. Genet., 16 (3), p. 585-600. 1993.

19 FALCÃO, J. N.; MOREIRA-FILHO, O.; BERTOLLO, L. A. C. An additional chromosome in two fish species. Braz. J. Genet., v. 7, n. 1, p. 109-118. 1984.

20 FELDBERG, E.; PORTO, J. I. R.; NAKAYAMA, C. M.; BERTOLLO, L. A. C. Karyotype evolution in Curimatidae (Teleostei, Characiformes) from the Amazon region. II. Centric fissions in the genus Potamorhina. Genome, v. 36, p. 372-376. 
1993.

21 FENOCCHIO, A. S.; BERTOLLO, L. A. C. Supernumerary chromosomes in a Rhamdia hilarii population (Pisces, Pimelodidae). Genetica, v. 81, p. 193-98. 1990.

22 FORESTI, F.; ALMEIDA-TOLEDO, L. F.; TOLEDO-FILHO, S. A. Chromosome studies in Gymnotus carapo and Gymnotus sp. (Pisces, Gymnotidae). Caryologia, v. 37, n. 1-2, p. 141-146. 1984.

23 FORESTI, F.; ALMEIDA-TOLEDO, L. F.; TOLEDO-FILHO, S. A. Regiões organizadoras de nucléolos em triplóides e híbridos interespecíficos de peixes. Cien. Cult., v. 38, p. 864. 1986.

24 GALETTI JR., P. M.; BERTOLLO, L. A. C.; MOREIRA-FILHO, O. Trends in chromosome evolution of neotropical characiform fishes. Caryologia, v. 47, p. 289298. 1994.

25 GALETTI JR., P. M.; LIMA, N. R. W.; VENERE, P. C. A monophyletic ZW sex chromosome system in Leporinus (Anostomidae, Characiformes). Cytologia, v. 60, p. 375-382. 1995.

26 GALETTI JR., P. M.; FORESTI, F.; BERTOLLO, L. A. C.; MOREIRA-FILHO, O. Heteromorphic sex chromosomes in three species of the genus Leporinus (Pisces, Anostomidae). Cytogenet. Cell. Genet., v. 29, p. 138-142. 1981.

27 GARRIDO-RAMOS, M. A.; JAMILENA, M.; LOZANO, R.; REJON, C. R.; REJON, M. R. Cloning and characterization of a fish centromeric satellite DNA. Cytogenet. Cell. Genet., v. 65, p. 233-237. 1994.

28 GARRIDO-RAMOS, M. A.; JAMILENA, M.; LOZANO, R.; REJON, C. R.; REJON, M. R. The Eco RI centromeric satellite DNA of the Sparidae family (Pisces, Perciformes) contains a sequence motive common to other vertebrate centromeric satellite DNAs. Cytogenet. Cell. Genet., v. 71, p. 345-351. 1995.

29 GERVAI, J.; PÉTER, S.; NAGY, L.; HORVATH, L.; CSANYI, V. Induced triploidy in carp, Cyprinus carpio. J. Fish. Biol., v. 17, p. 667-671. 1981.

30 HAAF, T.; SCHMID, M.; STEINLEIN, C.; GALETTI JR., P. M.; WILLARD, H. F. Organization and molecular cytogenetics of satellite DNA family from Hoplias malabaricus (Pisces, Erythrinidae). Chromosome. Res., v. 1, p. 77-86. 1993.

31 HOCHBERG, V. B. M.; ERDTMANN, B. Cytogenetical and morphological considerations on Rhandia quelen (Pisces, Pimelodidae). The ocurrence of $\beta_{-}$ chromosomes and polymorphic NOR regions. Braz. J. Genet., v. 11, p. 563-576. 1988.

32 HOWELL, W. M.; BLACK, D. A. Controlled silver staining of nucleolus organizer 
regions with a protective colloidal developer: a 1-step method. Experimentia, v. 36, p. 1014-1915. 1980.

33 JIM, S. M.; TOLEDO, V. Citogenética de Astyanax fasciatus e Astyanax bimaculatus (Characidae, Tetragonopterinae). Cien. Cult., v. 27, p. 1122-1124. 1975.

34 LEE, M. R.; ELDER, F. F. B. Yeast stimulation of bone marrow mitosis for cytogenetic investigations. Cytogenet. Cell. Genet., v. 26, p. 36-40. 1980.

35 LE GRANDE, W. H. Chromosomal evolution in North American catfishes (Siluriformes: ictaluridae) with particular emphasis on the madtoms, Noturus. Copeia, v. 1, p. 33-52. 1981.

36 LEVAN, A.; FREDGA, K.; SANDBERG, A. A. Nomenclature for centromeric position on chromosomes. Hereditas, v. 52, p. 201-220. 1964.

37 MAISTRO, E. L.; FORESTI, F.; OLIVEIRA, C.; ALMEIDA-TOLEDO, L. F. Occurrence of macro $\beta$-chromosome in Astyanax scabripinnis paranae (Pisces, Characiformes, Characidae). Genetica, v. 87, p. 101-106. 1992.

38 MARTINS, C.; GIULIANO-CAETANO, L.; DIAS, A. L. Occurrence of a $\beta$ chromosome in Cyphocharax modesta (Pisces, Curimatidae). Cytobios, v. 85, p. 247-253. 1996.

39 MESTRINER, C. A. Caracterização molecular e citológica do DNA repetitivo de Astyanax scabripinnis (Pisces, Characidae) portador de cromossomos supranumerários. São Carlos, 1997. 64 p. Tese (Doutorado). UFSCar.

40 MICHELLE, J. L.; TAKAHASHI, C. S. Comparative cytology of Tilapia rendalli and Geophagus brasiliensis (Cichlidae, Pisces). Cytologia, v. 42, p. 535-537. 1977.

41 MICHELLE, J. L.; TAKAHASHI, C. S.; FERRARI, I. Karyotypic studies of some species of the family Loricariidae (Pisces). Cytologia, v. 42, p. 539-546. 1977.

42 MOLINA, W. F. Cromossomos sexuais e polimorfismo cromossômico no gênero Leporinus (Pisces, Anostomidae). São Carlos, 1995. 177 p. Dissertação (Mestrado). UFSCar.

43 MOREIRA-FILHO, O.; BERTOLLO, L. A. C. Astyanax scabripinis (Pisces, Characidae): a complex species. Braz. J. Genet., v. 14, p. 331-357. 1991.

44 MOREIRA-FILHO, O.; BERTOLLO, L. A. C. Extraction and use of the cephalic kidney for chromosome studies in small fish. Braz. J. Genet., v. 14, p. 1085-1090. 1991.

45 MOREIRA-FILHO, O.; BERTOLLO, L. A. C.; GALETTI JR., P.M. Karyotipic studies of some species of family Parodontidae (Pisces, Cypriniformes). Caryologia, v. 38, n. 1, p. 47-55. 1985. 
46 MOREIRA-FILHO, O.; BERTOLLO, L. A. C.; GALETTI JR., P. M. Distribution of sex chromosome mechanisms in neotropical fish and description of a ZZ/ZW system in Parodon hilarii (Parodontidae). Caryologia, v. 46, p. 115-125. 1993.

47 MOREIRA-FILHO, O.; BERTOLLO, L. A. C.; GALETTI JR., P. M. Evidences for a multiple sex system with female heterogamety in Apareiodon affinis (Pisces, Parodontidae). Caryologia, v. 33, p. 83-91. 1980.

48 NELSON, J. S. Fishes of the world. John Wiley \& Sons Inc. 1984. 523 p.

49 OLIVEIRA, C.; FORESTI, F. Occurrence of supranumerary microchromosomes in Steindachnerina insculpta (Pisces, Characiformes, Curimatidae). Cytobios, v. 76, p. 183-186. 1993.

50 OLIVEIRA, C.; ALMEIDA-TOLEDO, L. F.; FORESTI, F. Revisão dos estudos citogenéticos em peixes neotropicais de águas continentais. In: VI Simpósio de Citogenética Evolutiva e Aplicada de Peixes Neotropicais. São Carlos, São Paulo, 104 p. 1996.

51 PASTORI, M. C.; FENOCCHIO, A. S.; LÓPEZ, P. A. First description of microchromosome in the Anostomidae fish Schizodon nasutus from Argentina. Braz. J. Genet., v. 20, p. 425-427. 1997.

52 PAULS, E.; BERTOLLO, L. A. C. Distribution of a supernumerary chromosome system and aspects of karyotypic evolution in the genus Prochilodus (Pisces, Prochilodontidae). Genetica, v. 81, p. 117-123. 1990.

53 PAULS, E.; BERTOLLO, L. A. C. Evidence for a system of supernumerary chromosomes in Prochilodus scrofa Steindachner, 1881 (Pisces, Prochilodontidae). Caryologia, v. 36, n. 4, p. 307-314. 1983.

54 PORTO, J. I. R.; FELDBERG, E.; FALCÃO, J. N.; NAKAYAMA, C. M. Cytogenetics studies in Hemiodidae (Ostariophysi, Characiformes) fishes from central amazon. Cytologia, v. 58, p. 397-402. 1993.

55 REFESTIE, T. Tetraploid rainbow trout produced by cytochalasin B. Aquaculture, v. 25, p. 51-58. 1981.

56 SALVADOR, L. B.; MOREIRA-FILHO, O. $\beta$-chromosome in Astyanax scxabripinnis (Pisces, Characidae). Heredity, v. 66, p. 50-56. 1992.

57 SCAVONE, M. D.; JÚLIO JR., H. F. Cytogenetics analysis and heterochromatin distribuition in ZZ/ZW sex chromosomes of the mailed catfish Loricariichtys platymetopon (Loricariidae: Siluriformes). Braz. J. Genet., v. 18, n. 1: 31-35. 1995.

58 SCHEEL, J. J. Fish chromosome and their evolution. Internal report of denmarks akvarium. Charlottenlund, Denmark, 22 p. 1973. 
59 STANGE, E. A. R.; ALMEIDA-TOLEDO, L. F. Supernumerary $\beta$-chromosomes restricted to males in Astyanax scabripinnis (Pisces, Characidae). Braz. J. Genet., v. 16(3). p. 601-615. 1993.

60 STREISINGER, G.; WALKER, C.; DOWER, N.; KNAUBER, D.; SINGER, F. Production of clones of homozygous diploid zebra fish (Brachydanio rerio). Nature, v. 291. p. 293-296. 1981.

61 SUMNER, A. T. A simple technique for demonstrating centromeric heterochromatin. Exp. Cell. Res., v. 75, p. 304-306. 1972.

62 TOLEDO, V.; FERRARI, I. Estudo citogenético em três espécies do gênero Pimelodus (Pimelodidae, Pisces). Científica, v. 4, p. 101-106. 1976.

63 UENO, K.; ARIMOTO, B. Induction of triploids in Rhodeus ocellatus by cold shock treatment of fertilized eggs. Experientia, v. 38, p. 544-546. 1982.

64 VARI, R. P. Phylogenetic relationships of the families Curimatidae, Prochilodontidae, Anostomidae and Chilodontidae (Pisces, Characiformes). Smithsonian contributions to zoology, n. 378: 60 p. 1983.

65 VENERE, P. C. Citogenética comparativa de peixes da família Curimatidae (Characiformes). São Carlos, 1991. 134 p. Dissertação (Mestrado). UFSCar.

66 VENERE, P. C. Diversificação cariotípica em peixes do médio rio Araguaia, com ênfase em Characiformes e Siluriformes (Teleostei, Ostariophysi). São Carlos, 1998. 61 p. Tese (Doutorado). UFScar.

67 VENERE, P. C.; GALETTI JR., P. M. Natural triploidy and chromosome $\beta$ in the fish Curimata modesta (Curimatidae, Characiformes). Braz. J. Genet., v. 7, p. 681687. 1985.

68 VENERE, P. C.; GALETTI JR., P. M. Chromosome evolution and phylogenetic relationships of some neotropical Characiformes of the family Curimatidae. Braz. J. Genet., v. 12, p. 17-25. 1989.

69 VICENTE, V. E.; MOREIRA-FILHO, O.; CAMACHO, P. M. Sex-ratio distortion associated with the presence of $\beta$-chromosome in Astyanax scabripinnis (Teleostei, Characidae). Cytogenet. Cell. Genet., v. 74, p. 70-75. 1996. 